\title{
CORRESPONDENCE
}

\section{Good as gold}

SIR - In the current debate on a gold standard the stumbling block is the fundamentally wrong premise in the quest to fix a price. It is not possible to fix a price for gold in terms of any existing currency. Far better to consider not a price but a value. Gold has a value as a medium of exchange, in other words as a currency. Consider the implications of using gold as money.

Assume all gold reserves minted into coins of standard weight and fineness. At a given date equate the number of coins so available with the figures used internationally in representing the price of goods and services in circulation. One coin will be found to equate to many hundreds of dollars.

Now start using only gold coins to pay for goods and services. Note the dramatic fall in the numbers on the price tickets (the first skirmish in the war on inflation). Continue to mint all newly-won gold into the standard coins. Charge the weight of gold going into industry or jewellery at the value of the equivalent number of coins. Paychecks would of course come down accordingly. Cheques and all paper transactions could be continued, but only against deposits in the equivalent number of coins. Gold money thus on deposit would pay interest whereas gold now in the bank does not.

The result would be a stable currency and stability of values. The gold-producing countries wold not get any richer (you can't eat gold) whereas countries with exports of commodities or manufactures, instead of suffering from "lack of hard currencies" would find their products are as good as gold.

This desirable state of affairs would continue as long as the supply of coins was adequate to satisfy the needs of international commerce. However, the rate of increase of the net worth of the world is historically greater than the rate of increase of gold production and is likely to remain so. In this situation the remedy would be to have a periodic revaluation of the value of the coin. Clearly this value is going to tend upwards and, as a concomitant, the numbers on the price tickets will go down - the very reverse of inflation. Gold thus produces capital gains.

The return to gold usage (rather than a gold standard) would provide a solution to currency and exchange problems and, since the money supply would be finite, a cure for inflation and a clear directive for monetary policy.

New York, USA

JOHN H. HARRIS

\section{Harsh words}

SIR - Your comments on Dr Rupert Sheldrake's book $A$ New Science of Life (Nature 24 September, p.245) are very harsh. One can hardly pretend that our current understanding of development and its genetic control is adequate. We should not even believe that it is oriented in the right direction. The concept of morphogenetic fields is neither unscientific nor without support from some distinguished embryologists. If the same concept is extended to all aggregations of matter, animate or otherwise, it may be considered as a bold, hazardous, foolhardy or unwarranted generalization, depending on one's attitude towards new thought. Just a hundred years ago if somebody suggested that the sequence of nucleotides in DNA constitutes the information required to make a fly, a frog or a man from a small bit of cytoplasm it would have been dismissed as preposterous. If there is no obvious way of testing experimentally Dr Sheldrake's hypothesis of formative causation, it does not preclude its possibility in the future.

Many embryological theories depend on recourse to morphogenetic fields in spite of the recent progress in genetics and molecular biology. No real progress can be made in understanding the importance of these fields without identifying the nature of the variables along the gradients. Perhaps the only measurable variable to which the origin of a gradient can be traced is the concentration of diffusing substances. Positional information which adds a new dimension to the concentration of diffusing substances is also now accepted as a fundamental mechanism of morphogenesis. However, even these powerful theoretical tools have not successfully accounted for any single embryological event. In fact it would be preposterous to assume that development of complex organisms can be explained solely on the basis of the current theoretical platform on which molecular biology stands. Recourse to new conceptual framework and unconventional mechanisms is imperative to understanding complex biological processes such as morphogenesis.

University of Zoology,

K. VASUdeva Ra() University of Delhi, Delhi, India.

\section{Page charges}

SIR - Frank Close's review of high-energy physics journals in Nature 1 October (p.369) reveals a misconception that may be widespread enough to warrant correction in public. I refer to his statement that "in times of financial stringency European authors are often unable to publish there [in Physical Review] as a result of page charges". The fact is that the page charge system, not only in Physical Review (including Physical Review Letters) but in all journals published by the American Institute of Physics, is a voluntary one. Payment of page charges is requested, but acceptance of a contribution is not conditioned by whether page charges are paid. The only effect of nonpayment is a delay in publication; and even that is not imposed on papers in Physical Review Letters, or on the newly instituted rapid communications section in Physical Review.

I hope I will not be misconstrued as urging authors to submit papers to our journals and not honour the page charges when they are in a position to pay them. I do not even mean to solicit papers for the journals. Those costs that are not met by page charges have to be made up from higher subscription costs for persons and institutions that are not members of the various societies; and we are as concerned as anyone else over the effects of ever higher costs to libraries. I do feel, however, that it is important that the true state of affairs be completely understood.

George L. Trigg Physical Review Letters, (Editor) New York, USA

\section{Belgium's power}

$\mathrm{SIR}_{\mathrm{R}}-$ Your recent article on nuclear safety in Belgium (Nature 24 September, p.249) prompts me to explain some points about Belgium's approach to nuclear power.

First, the nuclear power station licensing procedure in Belgium involves two stages: (1) on approval of all planning and logistical aspects and the safety guidelines, permission is granted for construction to start and (2) after subsequent safety analysis and approval, permission is granted to put the power station into operation.

During plant construction there is continued liaison between the public authorities, technical experts, suppliers and the station owner, to ensure that all safety aspects are in line with the Belgian regulations. This process involves the exchange of about 2,000 questions and answers, and has the advantage that the most modern safety innovations are incorporated into Belgian nuclear power stations at an early stage. This could clearly not happen if the design had to be frozen at the time of the construction permit.

Given the long construction period required for such plants, this procedure eliminates the problem of premature technological obsolescence. It is also interesting to note that Belgium is the only country to submit nuclear power station designs for approval to a committee of international (EEC) experts.

Second, the question of the number of specialists of ficially appointed to deal with nuclear safety was somewhat misrepresented in your article. Belgian law confers supervisory authority for the nuclear sector to a stateapproved inspection organization, Vinçotte. Other official government bodies, however, exercise ultimate control in this field. So in fact there are many more than the 17 Vincotte inspectors involved in supervising the safety of the Belgian nuclear power stations.

On the other hand, although it is true that the International Atomic Energy Agency has cited the figure of 50 experts as a standard force to deal with nuclear safety in a country like Belgium, the responsibilities of such a force would include operational control, regulatory missions, evacuation plans and so on, in addition to overseeing general safety precautions. In Belgium these aspects are not neglected, but are properly dealt with by the governmental bodies and technical experts mentioned above, (including the "Commission for questions concerning radiation').

Finally, with respect to the threatened strike by the employees of Vinçotte, their qualms did not stem from questions of power plant operations, but rather from the uncertåinty of their career prospects.

So to summarize, (1) the procedure followed by the utilities before putting a nuclear power plant in operation strictly follows Belgian law - the strictest in the world, according to IAEA. And (2) the force of experts and inspectors in charge of safety supervision is perfectly adequate, both in number and competence, and is in a position to enforce the nuclear safety regulations, as it has indeed done (nuclear power stations have been operating in Belgium for 20 years).

$$
\text { R. VAN IFAN DANim: }
$$

Societé Intercommunale Belge de

Gaz et d'Electricite, Brussels, Belgium 